\title{
The impact of price disclosure on dynamic shopping decisions
}

Citation for published version (APA):

Dellaert, B. G. C., Golounov, V. Y., \& Prabhu, J. (2005). The impact of price disclosure on dynamic shopping decisions. METEOR, Maastricht University School of Business and Economics. METEOR Research Memorandum No. 007 https://doi.org/10.26481/umamet.2005007

Document status and date:

Published: 01/01/2005

DOI:

10.26481/umamet.2005007

Document Version:

Publisher's PDF, also known as Version of record

\section{Please check the document version of this publication:}

- A submitted manuscript is the version of the article upon submission and before peer-review. There can be important differences between the submitted version and the official published version of record.

People interested in the research are advised to contact the author for the final version of the publication, or visit the DOI to the publisher's website.

- The final author version and the galley proof are versions of the publication after peer review.

- The final published version features the final layout of the paper including the volume, issue and page numbers.

Link to publication

\footnotetext{
General rights rights.

- You may freely distribute the URL identifying the publication in the public portal. please follow below link for the End User Agreement:

www.umlib.nl/taverne-license

Take down policy

If you believe that this document breaches copyright please contact us at:

repository@maastrichtuniversity.nl

providing details and we will investigate your claim.
}

Copyright and moral rights for the publications made accessible in the public portal are retained by the authors and/or other copyright owners and it is a condition of accessing publications that users recognise and abide by the legal requirements associated with these

- Users may download and print one copy of any publication from the public portal for the purpose of private study or research.

- You may not further distribute the material or use it for any profit-making activity or commercial gain

If the publication is distributed under the terms of Article $25 \mathrm{fa}$ of the Dutch Copyright Act, indicated by the "Taverne" license above, 


\title{
The Impact of Price Disclosure on Dynamic Shopping Decisions
}

\author{
Benedict G.C. Dellaert ${ }^{1}$ \\ Vladislav Y. Golounov ${ }^{2}$ \\ Jaideep Prabhu ${ }^{3 *}$
}

February 2005

${ }^{1}$ Department of Marketing, Faculty of Economics and Business Administration, Maastricht University, PO Box 616, 6200 MD Maastricht, The Netherlands, email: b.dellaert@mw.unimaas.nl, phone: +31 43388 3250, fax: +31 433884918

${ }^{2}$ Lukol Networks, Frankenlaan 33, 5037 KE Tilburg, The Netherlands, email: support@lukol.com, phone:+31 134675388

${ }^{3}$ Tanaka Business School, Imperial College London, South Kensington campus, London SW7 2AZ, United Kingdom, email: J.Prabhu@imperial.ac.uk, phone: +44 207594 9109, fax: +44 2078237685

\footnotetext{
*We gratefully acknowledge a Tilburg University, Faculty of Economics and Business Administration grant for data collection through the CentERdata-panel. We thank Henk op den Brouw for programming most of the experimental shopping environment used in this study, and Joao Assunçao, Gerald Häubl, Jeff Inman, Gaby Odekerke-Schröder, Arthur van Soest, JanBenedict Steenkamp, Michel Wedel and participants in a seminar at the University of Cambridge for valuable comments. Part of the first author's research on this project was funded by the Dutch Science Foundation (NWO-ESR). At the time of this research, the second author was a Ph.D. student funded by the SOBU cooperation program between Tilburg University and Eindhoven University of Technology.
} 


\title{
The Impact of Price Disclosure on Dynamic Shopping Decisions
}

\begin{abstract}
A potentially powerful way to assist consumers in making dynamic shopping decisions is to disclose price information to them before they shop, for example by posting prices on the Internet. This paper addresses the differential impact of disclosing either only current, or both current and future prices, on consumer shopping decisions in multi-period tasks involving multiple product purchases. In the context of an Internet-based experiment, we find that consumer expenditure deviates more strongly from that of a normative model when both current and future prices are disclosed than if only current prices are disclosed. We investigate the behavioral effects underlying this finding by estimating a model that allows for variations in consumer discounting, strength of store price format preferences, as well as choice consistency between different price disclosure conditions.
\end{abstract}

Key words: Consumer behavior, Dynamic choice models, Consumer decision-making, Price disclosure 
Increasingly, online technology such as the Internet enables consumers to obtain price information before they incur the costs of traveling to a store. Traditionally, retailers provided some price information to consumers in their homes, for instance through newspaper advertisements and TV commercials. Online retailers, however, typically present in a systematic and logical manner all current prices directly to consumers in their homes. In some instances, advanced information technology is even used to provide information to consumers on future prices. For example, both online and traditional retailers now use direct personalized e-mails to pre-announce specials to valued loyal customers.

Although previous research suggests that lowering the search costs for price information increases consumer welfare (e.g., Brynjolfsson and Smith, 2000) and that more transparent deal patterns allow consumers to reduce shopping expenditure over time (Krishna, 1994a), little is known about how consumers actually incorporate such information in their shopping decisions and if different levels of price disclosure affect consumers’ decisions differently.

In this study we address these latter two questions by investigating how the disclosure of current prices, and current and future prices, affects consumers' dynamic shopping decisions relative to a normative model. Drawing on previous research on the effects of task complexity on consumer decision-making (e.g., Bettman et al., 1993; Swait and Adamowicz 2001a, b) and the behavioral theory of dynamic consumer decisions (e.g., Meyer and Assunçao, 1990; Hutchinson and Meyer, 1994) we hypothesize how consumer performance relative to a normative model changes depending on the level of price disclosure. We investigate how three behavioral effects—variations in consumer discounting, strength of store price format preference, and choice consistency—explain observed differences in relative performance. We do this by first extending a normative model of consumers’ dynamic shopping decisions to incorporate these 
behavioral effects. We then estimate this model on data from an Internet-based experiment in which consumers make store choice and purchase quantity decisions over time and are rewarded on the basis of minimizing their overall shopping expenditure.

\section{The effect of price disclosure on dynamic shopping decisions}

Normatively speaking, increasing information on current and future prices should enable consumers to achieve lower expenditure. Specifically, information on future discounts should enable consumers to plan ahead more effectively and thus choose stores and purchase quantities in such a way that they benefit from a greater number of future discounts. Indeed, empirical research supports the general conclusion that more detailed information improves dynamic decision-making (e.g., Erdem and Keane, 1996; Krishna 1994a, b). Behaviorally oriented empirical research, however, also shows that consumers' choices deviate systematically from those predicted by normative models of dynamic choice, and that consumers are unlikely to employ dynamic optimization rules to their full extent (see Meyer and Assunçao, 1990).

We combine these two views to examine if different levels of price disclosure affect consumers' decisions differently. In particular, we hypothesize that although increasing levels of price disclosure improves consumers’ dynamic shopping performance (by lowering overall expenditure), this also makes it harder for consumers to effectively 'live up to' a normative decision-making model.

Increasing information about current and future prices increases task complexity for consumers because it requires them to take into account a greater number of decision factors so as to fully benefit from this information (c.f., Bettman, Johnson and Payne, 1990). We investigate three behavioral effects that potentially explain the differential impact on consumers' decision performance based on these changes in task complexity. The first effect is consumers' limited ability to be forward-looking in their dynamic decision-making. There is considerable 
evidence that in making dynamic decisions, consumers are less forward-looking than normative models prescribe (e.g., Meyer and Assunçao, 1990). In contexts in which no (or very little) information on current and future events is available, normative economic theory shows that there is little to gain from forward planning (c.f., DeGroot, 1970). Thus, in such cases, consumers' dynamic decision-making requires little forward-looking. When more information is available, however, consumers' relative inability to incorporate future discounts into their decision-making affects their performance more strongly, leaving their performance more greatly impaired relative to a normative model that fully incorporates this information. Therefore we expect that as more information about current and future prices becomes available, consumers' limited ability to be forward-looking will affect their performance more strongly relative to a normative model.

Second, from research in static contexts, we know that consumers respond to increased task complexity by adopting simplifying strategies in making decisions (c.f., Bettman et al., 1993). In the context of our study, we expect that one such simplifying strategy is likely to be consumers' use of store price format as a decision variable, specifically whether the store in question follows an EDLP or Hi-Lo price format. This heuristic is consistent with recent research that shows that a major feature of consumers' simplifying strategies when faced with task complexity is a stronger focus on alternative specific constants (e.g., brands) (Swait and Adamowicz 2001a). Normatively, when purchasing a fixed product basket, consumers should base their shopping decisions exclusively on their expected expenditure of buying in different stores. We expect, however, that in order to simplify their choices, consumers will develop store price format preferences over and above their rational expectations for spending in each store. 
A third (and related) behavioral effect of task complexity we expect is that consumer choices become less consistent as levels of price disclosure increase. Research in static decisionmaking shows that the reliability with which consumers' utilities relate to the choices they make (i.e., consumers' choice consistency) becomes smaller across different choice sets as the composition of these choice sets becomes more complex (e.g., Dellaert, Brazell and Louviere, 1999; Swait and Adamowicz, 2001b). We expect that a similar effect occurs when consumers are faced with more complex dynamic decision tasks such as those we study.

\section{Formal model}

We first develop a normative model as a base and then add to it the three behavioral effects discussed above. The assumptions of the normative model are similar to those in previous research (e.g., Krishna, 1994a) and are based on realistic marketing scenarios (see Appendix 1). Nevertheless, it is worth noting that our model is in some ways, unavoidably, a simplification of reality; for instance, we do not allow for flexible consumption (e.g., Bell, Chiang and Padmanabhan, 1999). In our experiment, however, we control for such simplifications in our model's features by constructing subjects' task accordingly (see section 3.1 below and Appendix 1 for details).

In each shopping period, the consumer faces the optimization problem of choosing where to shop and how much to buy to meet his or her (current and future) consumption goals so that total shopping expenditure over time is minimized. Let $N$ be the set of all products $n, I$ the set of consumers $i$, and $S$ the set of stores $s$. On each trip consumers choose one store to purchase their groceries, where $s_{t} \in S$ is the store chosen by the consumer in week $t$. Let $q_{n t \alpha}$ be the quantity purchased of product $n$ in week $t$ at $\alpha$, a price index as defined below. Now, the consumer faces the problem of minimizing his or her shopping expenditure in a time horizon of $T$ weeks 
$(t=1, \ldots, T)$, where $\mathrm{T}$ is the time horizon in the experiment. The total cost of a shopping trip is determined by the costs of the products purchased on that trip plus the monetary equivalent of the preference for visiting a store. If consumption goals are known and perfect product substitutability across stores is assumed, product utility does not enter the optimization task. Thus, each consumer $i$ faces the multi-period optimization problem of minimizing the expected cost for each period $t$ subject to constraints based on his or her weekly consumption needs and stocking restrictions. Let $\alpha$ be the index of possible prices, with respective probabilities $\operatorname{Pr}\left(p_{n s_{t} \alpha}\right)$ where $\alpha$ is an element of $\Psi_{n s t}$ - the set of indexes for possible prices for product $n$ in store $s$ at time $t$. For notational simplicity we do not include a subscript to indicate the fact that all parameters are estimated specifically for a given level price of disclosure. Then, consumer $i$ 's expected costs for a purchase quantity $q_{n t \alpha}$ of product $n$ at store $s$ in period $t$ given price $p_{n s_{t} \alpha}$ is defined as follows:

$$
E_{i}\left(q_{n t \alpha} p_{n s_{t} \alpha}\right)=\sum_{\alpha \in \Psi_{n s t}} \operatorname{Pr}\left(p_{n s_{t} \alpha}\right) q_{n t \alpha} p_{n s_{t} \alpha}
$$

Let $Q_{t}$ be the feasible set of purchases which satisfy the relevant conditions. The effect of discounting future events is introduced by including a discount factor $\gamma$ that captures the fact that future expected costs may be discounted with a discount coefficient $e^{(z-t) \gamma}$ (exponential discounting). We can now write out the consumer's dynamic cost minimization problem in terms of the following two interrelated decisions that are repeated in all periods $t$. Though the consumer minimizes expenditure jointly over these two decisions, they are separated, because if consumers do not know the price in each store before they go there, they need to reconsider their purchase quantity decision once they are in the store and know its current prices. If consumers do have all stores' current prices before they shop, then the two decisions are combined into one. 
1. 'Store and expected purchase quantity choice'. To make a store choice at time $z$, the consumer minimizes the following function by choosing a store for the current period, while anticipating their potential store choices in remaining periods $(t=z, . ., T)$ as well as the quantities for these periods:

$$
\sum_{t=z}^{T} e^{(z-t) \gamma} \sum_{n \in N} E_{i}\left(q_{n t \alpha} p_{n s_{t} \alpha}\right) \quad q_{n t \alpha} \in Q_{t}, \alpha \in \Psi_{n s t}
$$

2. 'Purchase quantity choice'. After making the store choice, the consumer enters the store and has the opportunity to observe the actual prices $p_{n s_{z} \alpha}$ in the store. Therefore, the consumer then minimizes the following 'updated' function by choosing $q_{n z \alpha}, q_{n t \alpha}$ and $s_{t},(t=z+1, \ldots, T)$ :

$$
\sum_{n \in N} q_{n z \alpha} p_{n s_{z} \alpha}+\sum_{t=z+1}^{T} e^{(z-t) \gamma} \sum_{n \in N} E_{i}\left(q_{n t \alpha} p_{n s_{t} \alpha}\right) \quad q_{n t \alpha} \in Q_{t}, \alpha \in \Psi_{n s t}
$$

The above two steps describe the consumer's optimization for any week. The optimization problem over all periods is then solved by backward induction (Bellman, 1957). The solution to this optimization is outlined in the technical appendix to the paper.

Now, we extend this base-model to account for variations in discounting that express differences in the degree to which consumers are forward-looking. To do so, we include an additional discount factor $\delta$ that captures the fact that future expected costs may be discounted with a discount coefficient that differs from the normative rate $\gamma$. If consumers are less forwardlooking than the normative model, then $\delta$ will be significant.

We also capture consumers’ baseline preferences $\beta$ for visiting stores $s_{t}$ with different price formats. Specifically, we introduce a variable $R_{s_{t}}$ which may differ, for example, between stores with EDLP or Hi-Lo price formats. We allow consumer preferences for store price formats 
to differ across levels of price disclosure as a means of capturing consumers' reliance on store price formats as a driver of their shopping decisions.

We also introduce error in the model to allow for deviations between observed consumer decisions and the proposed model and to be able to estimate the statistical significance of the behavioral effects. To this end, we assume that within each price disclosure condition, errors are independently and identically Gumbel distributed, but that between price disclosure conditions error variance may differ. Such error differences may be due to, for example, differences in the difficulty of making choices between the price disclosure conditions. Finally, as we mention above, the consistency with which consumers make their decisions varies depending on choice complexity (e.g., Swait and Adamowicz, 2001b). To capture this effect, we introduce a scale parameter $\lambda$ that is inversely related to the error component in the model (e.g., Allenby and Ginter, 1995). ${ }^{1}$ Dividing the store price format preference by the scale parameter also allows us to express the entire model in monetary terms.

Let $C 1\left(s_{z}\right)$ be the expected costs in decision stage 1 of choosing store $s_{z}$ in week $z$, and $C 2\left(\mathbf{q} \mathbf{2}_{\mathbf{z}}\right)$ be the expected costs in decision stage 2 of choosing purchase quantity basket $\mathbf{q} \mathbf{2}_{\mathbf{z}}$ in week $z$. Let $\varepsilon 1_{z}$ and $\varepsilon 2_{z}$ be the error terms in observing these costs respectively. Then, the econometric model for decision stages 1 and 2 can be expressed as follows:

1. 'Store and expected purchase quantity choice'

$$
C 1\left(s_{z}\right)=\sum_{t=z}^{T}\left\{e^{(z-t)(\gamma+\delta)}\left[\frac{\beta}{\lambda} R_{s_{t}}+\lambda \sum_{n \in N} E_{i}\left(q_{n t \alpha} p_{n s_{t} \alpha}\right)\right]\right\}+\varepsilon 1_{z}
$$

\section{2. 'Purchase quantity choice'}

\footnotetext{
${ }^{1}$ Note that improving estimation efficiency by assuming one error scale across all price disclosure conditions was not feasible for two reasons. First, it is not possible to disentangle the combined effect of error scale and structural parameters within each price disclosure condition. Second, none of the other parameters can be used as a basis for scaling the estimates across conditions.
} 


$$
C 2\left(\mathbf{q} \mathbf{z}_{\mathbf{z}}\right)=\sum_{n \in N} q_{n z \alpha} p_{n s_{z} \alpha}+\sum_{t=z+1}^{T}\left\{e^{(z-t)(\gamma+\delta)}\left[\frac{\beta}{\lambda} R_{s_{t}}+\lambda \sum_{n \in N} E_{i}\left(q_{n t \alpha} p_{n s_{t} \alpha}\right)\right]\right\}+\varepsilon 2_{z}
$$

Thus, we can model both the store choice and the purchase quantity decision within each level of price disclosure and for each period $t$ using the multinomial logit model. The probability that individual $i$ chooses $s_{t}$ in period $t$ is:

$$
\operatorname{Pr}_{i}\left(s_{t}\right)=\frac{e^{-C 1\left(s_{t}\right)}}{\sum_{s_{t}^{\prime} \in S} e^{-C 1\left(s_{t}^{\prime}\right)}}
$$

If we denote the set of all possible purchase baskets in decision stage 2 of period $t$ as $Q 2_{t}$, the probability of choosing the basket of purchases $q 2_{t}$ by individual $i$ is:

$$
\operatorname{Pr}_{i}\left(q 2_{t}\right)=\frac{e^{-C 2\left(q 2_{t}\right)}}{\sum_{q 2_{t}^{\prime} \in Q 2_{t}} e^{-C 2\left(q 2_{t}^{\prime}\right)}}
$$

We estimate this model by maximizing the log-likelihood function for the joint choice of store and purchase quantity. If we define:

$$
\theta 1\left(s_{t}\right)=\left\{\begin{array}{ll}
1 & \text { if } s_{t} \text { is chosen } \\
0 & \text { otherwise }
\end{array} \quad \text { and } \quad \theta 2\left(q 2_{t}\right)= \begin{cases}1 & \text { if } q 2_{t} \text { is chosen } \\
0 & \text { otherwise }\end{cases}\right.
$$

then the likelihood function is expressed as:

$$
\log L I K=\sum_{i \in I}\left\{\sum_{t=1}^{T}\left(\sum_{s_{t} \in S}\left\{\theta 1\left(s_{t}\right) \ln \left[\operatorname{Pr}_{i}\left(s_{t}\right)\right]\right\}+\sum_{q 2_{t} \in Q 2_{t}}\left\{\theta 2\left(q 2_{t}\right) \ln \left[\operatorname{Pr}_{i}\left(q 2_{t}\right)\right]\right\}\right)\right\}
$$

\section{Shopping expenditure game}

We developed an Internet-based shopping game as the context within which to investigate the effect of different levels of price disclosure on consumers' dynamic shopping decisions. We designed the game to achieve maximum possible realism while still ensuring a rigorous context within which to manipulate the independent variables of interest to our study. 
The shopping game was developed in an Internet-context using HTML and subjects played it for multiple periods (weeks).

\subsection{Description of the Internet-based shopping game}

The game was designed to have the following features. The main web page welcomed subjects to the game and gave them instructions on the rules and objectives of the game as well as the decisions they were required to make. The page informed subjects that they were required to play the role of consumers who needed to buy three food items- bread, cookies and milkevery week over a period of thirty weeks. Subjects’ consumption goals were identical for all versions of the game and required them to consume one item of each product per week. The same page also informed subjects that their objective in the game was to minimize their expenses over the thirty week period by intelligently choosing the stores where they shopped and how much stock they kept at home. Subjects were told they would receive 10 Euros if they were among the top $10 \%$ of performers in (their version of) the game in terms of overall spending. This reward structure ensured that normatively subjects would aim to minimize total spending in the game and would not discount spending in later periods of the game.

Next, subjects were instructed that every week they could choose to shop at only one of two possible stores. Subjects were told they could change stores from week to week but that, because of traveling time and costs, it was not possible to visit both stores in the same week. Additionally, the game was programmed to ensure that in each week subjects could visit only one store. Second, they were told that the traveling costs and time were identical for both stores so that search costs did not influence store choice. Store design was also identical for both stores and we indicated that all stores carried perfect substitutes for all products. Third, subjects were informed about each store's price format and that this format remained the same throughout the 
game. Fourth, subjects were told that milk could not be stored; this forced them to visit a store every period of the game. Bread and cookies could be stored for a maximum of one week to ensure that being forward-looking was necessary but relatively simple. If in any week subjects attempted to overstock they received a message that their stock would spoil. The game would then force them to re-enter the quantity they wished to purchase. Fifth, to simplify subjects' minimization task they were given sufficient budgets to allow for maximum stocking in each period if they so wished.

Once subjects had read the instructions on the main web page, they clicked to proceed with the shopping game. The game itself consisted of three sequential web pages. The first page was the subject's “Home” page. This page provided the subject's current budget, the (fixed) current week's consumption needs and the subject's current stock. When subjects had read the information on this page, they clicked to move to the next page that was the "Shopping Mall" page. This page provided information on the two stores from which subjects could choose to shop. Of these stores, one always followed a Hi-Lo price format, namely it featured occasional deep discounts and a regular price otherwise. The other store always followed an EDLP price format, meaning it always featured a fixed low price. The level of information on current and future prices in the two stores was varied on this page to achieve the desired manipulations for our different experimental conditions as described below.

After reading this page, subjects clicked on the store which they wished to shop in and moved to the third and final page which was the "Store" page (each store was programmed to have its own "Store" page). On this page, subjects were provided with information on the prices of the three items in the store for that week. (Depending on the manipulations, further information on prices in the store for the next week could also be provided on this page.) When 
subjects had read the information provided on this page, they selected the quantity of each product they wished to purchase from the store for that week. After making their purchase, the program returned subjects to their "Home” page. The "Home” page now reported subjects' stock automatically updated to include their most recent purchases and the following week's consumption needs. In this manner, the shopping cycle repeated until the end of thirty weeks when the game automatically terminated with a page thanking subjects for their participation.

\subsection{Experimental design}

We employed a 3 (price disclosure level) X 2 (store price patterns) X 30 (weeks) full factorial design. The first two factors—price disclosure level and store price patterns—-were between-subjects manipulations, while the third factor — weeks—was a within-subjects manipulation.

We explicitly manipulated the price information provided to subjects. The three levels of price information were: information on stores' general price format only (no price disclosure), information on general price format and the current week’s prices (current price disclosure), and information on general price format, current and following week's prices as well (future price disclosure). In addition to the price disclosure level manipulation, we also varied the specific store price patterns in the two stores that subjects could choose from. Note that we distinguish between a store's price format and its actual price pattern. Researchers typically distinguish between two archetypical retail price formats: 1) stores where prices are known to the consumer and are stable (i.e., EDLP stores) and 2) stores where prices are unknown and may or may not be discounted (i.e., Hi-Lo stores) (e.g., Bell and Lattin, 1998). The two stores in our experiment each followed one of these two store price formats. 
To prevent confounding of store price format preferences with actual price patterns, we developed two separate store price pattern conditions: one in which the Hi-Lo and another in which the EDLP store was preferred by the normative model. Each store price pattern was developed for all three price disclosure conditions. The actual price process for each price pattern was such that prices were drawn with equal probability from an equidistant set of possible prices. The expected value of these draws differed between the two store price pattern conditions. There was no correlation between prices in subsequent periods. We pool data from the two price pattern conditions in our model estimation.

\subsection{Procedure}

Subjects were randomly assigned to one of the 6 between-subjects experimental conditions. In all conditions, subjects played a trial version of the game before starting the actual experiment. This was done to ensure that subjects were familiar with how the game itself was played before they participated in the actual experiment. Subjects were required to play at least 10 rounds of the trial game, but could play up to 30 rounds if they wished. The trial game was identical in structure to the actual game. However, the prices used in the trial game were different from those used in the real game and subjects were informed of this in advance.

In the no price disclosure conditions, subjects did not receive information on either current or future prices before entering a store. However, subjects were informed about each store's general price format. Further, a key feature of the optimal model is that subjects have stable, known beliefs about the distributions of prices they face. To ensure this, we provided subjects with the following information. With respect to the Hi-Lo store, subjects were informed about the price range in the store as well as the probability of price promotion. With respect to the EDLP store, for which prices remained fixed throughout the experiment, subjects were told 
the store's prices at the start of the experiment. This feature was repeated in the current price disclosure and future price disclosure conditions.

In the current price disclosure conditions, in addition to the information provided in the no price disclosure conditions, subjects were also given information every week on the current prices in the store before entering a store. The future price disclosure conditions differed from the other two conditions in that subjects were provided information on both the current and following week’s prices for the stores. Given that consumers could stock only one period in advance, they would highly benefit from knowing a product's price one period ahead of time, but would benefit relatively less from knowing a product's price two or more periods in advance.

\subsection{Subjects}

Subjects were members of a long-standing panel of Dutch consumers set-up and managed for research purposes by Tilburg University in the Netherlands. The panel consists of approximately 2000 individuals in 1500 households, and is largely representative of the population in terms of general characteristics such as age, sex, income, education and geographical location. Panel members respond voluntarily to consumer surveys that are run on a weekly basis and use a modem to gain access to the surveys. All members of the panel have access to home computers. Because the panel is not selected on the basis of PC ownership, subjects that do not have their own PC receive a basic configuration from the organization that runs the panel. In all there were 6 versions of the game corresponding to the 6 experimental conditions: 3 levels of price disclosure (games 1, 2 and 3) and 2 store price patterns (versions a and $b$ within each game). Subjects were screened on the basis of having a minimum of Internet experience to be able to participate in the study. Half of this group (a randomly drawn subset of

421 subjects) were contacted for participation in the study, of which 258 participated in the game 
and 187 completed the game successfully. The main reason for not completing the game was a break-down in the subject's connection to the Internet. The number of subjects in each version of the game was 27, 34, 31, 32, 36 and 27 for games 1a, 1b, 2a, 2b, 3a and 3b respectively. All participants used the Internet to access the game and responded within four days after receiving the invitation to participate, which is the customary response period for the panel.

\section{Results}

We first analyzed subjects' overall spending in the different price disclosure conditions. Table 1 presents the results. As expected, subjects' absolute expenditure decreased as information levels increased. One-tail $t$-tests of the difference between subjects' spending in the different information conditions revealed that spending was significantly lower in higher price disclosure conditions. Specifically, spending decreased from 266.6 to 243.6 to 237.2 for games 1a, 2a and 3a (all differences significant at $\mathrm{p}<0.05$ ) and from 266.1 to 241.0 to 236.4 for games $1 \mathrm{~b}, 2 \mathrm{~b}$ and $3 \mathrm{~b}$ (all differences significant at $\mathrm{p}<0.05$ ). The improvement was greatest in moving from the no price disclosure to the current price disclosure condition (23 and 25.1 for the a and b games respectively).

We then compared the improvement in spending of subjects' actual choices as information increased with the corresponding improvement in spending of the normative model. These differences showed that initially, as price disclosure increased, subjects were able to reap the benefits of using the additional price information. Specifically, in going from the no price disclosure to the current price disclosure condition, the average reduction in subjects' actual spending was almost equivalent to the reduction in spending in the normative model (23 vs. 24.8 for the Hi-Lo preferred games and 25.1 vs. 25.1 for the EDLP preferred games). However, in moving on to the future price disclosure conditions, subjects' actual reduction in spending was lower than the optimal reduction (6.4 vs. 11.1 and 4.6 vs. 8.7 for the Hi-Lo and EDLP preferred 
games respectively). One-tail $t$-tests showed that these differences were statistically significant at the $90 \%$ and $95 \%$ confidence levels respectively ( $p<0.10$ and $\mathrm{p}<0.05$ respectively). Therefore, in support of our hypothesis, subjects performed relatively less well than the normative model as price disclosure increased from information on current prices only to information on both current and future prices.

Next, we investigated the role of reduced forward-looking behavior in explaining subjects' deviation from the normative model. To do so, we estimated the model in section 3 for each of the three price disclosure conditions, pooling the data across the two price patterns ( $\mathrm{n}=59,70$ and 58 respectively). Table 2 reports the results of the estimation ${ }^{2}$. In interpreting the results we first note that, according to normative theory, subjects should be completely forwardlooking (i.e., no discounting should occur). This is the case because subjects in our experiment were rewarded on the basis of their total performance at the end of the game. Thus, we controlled for normative discounting in our experimental set-up. Therefore, a significant estimate of the discounting parameter in the model demonstrates choice behavior by the subject that is less forward-looking than the normative model would prescribe (i.e., stronger than normative discounting). Subjects should also have no systematic preferences for one store price format over the other because all differences between stores are accounted for by price only (i.e., products in both stores are identical in the experiment).

We find that subjects are less forward-looking than the normative model for the current price disclosure $(\delta=.937, \mathrm{p}<.05)$ and future price disclosure $(\delta=.436, \mathrm{p}<.05)$ conditions, but not for the no price disclosure condition ( $\delta=.086, \mathrm{p}>.10)$. We also find that subjects have a

\footnotetext{
${ }^{2}$ We also estimated a latent class version of our model allowing for heterogeneity in discount rates. Although this analysis showed that 2-3 segments existed, the results did not lead to differences in interpretation. We only report the more parsimonious aggregate results here. The detailed results are reported in the technical appendix to the paper.
} 
preference for the Hi-Lo price format over the EDLP price format in all three conditions ( $\beta=.184, \mathrm{p}<.05 ; .469, \mathrm{p}<.05$; and $0.343, \mathrm{p}<.10$ in games 1,2 and 3 , respectively). We next turn to the estimate of the scale parameter in the model. Recall that the size of this parameter is inversely related to the standard deviation of the error component. Thus, our findings indicate that the error variance is smallest in the current price disclosure condition $(\lambda=-1.527, \mathrm{p}<.05)$ suggesting that subjects' decision making is most consistent in this condition.

\section{Discussion}

In contrast to past research, which has developed normative models of the role of price information in dynamic choice (e.g., Erdem and Keane, 1996; Krishna 1994a,b) or has emphasized behavioral deviations from normative models (e.g., Meyer and Assunçao, 1990), we investigate how consumers' deviations from normative models of dynamic decision-making vary with different levels of price disclosure. A second, related contribution of this paper is that it sheds light on the reasons why, in dynamic tasks, price disclosure improves consumers' absolute performance, but not relative performance (compared to a normative model).

We now discuss this second contribution in detail. Given that we find that discounting is significant in the current disclosure condition, but that relative decision performance is no worse in this condition than in the no price disclosure condition, we conclude that reduced forwardlooking can only partially explain a shift in subjects' decision performance relative to the normative model. Similarly, the fact that consumers' preference for store price format was significant in all three price disclosure conditions explains why subjects don't perform as well as the normative model in general, but not why they perform progressively worse than the normative model when going from the current to future price disclosure condition. The combined effects of reduced forward-looking and the observed shifts in choice consistency 
perhaps offer the most likely explanation for our findings. We observe that the high choice consistency in the current price disclosure condition compensates for the increased impact of reduced forward-looking in this condition.

To explore possible heuristics that consumers may have used, we studied the choice patterns of the different subjects that performed well in each game. This was done by analyzing the choices that these subjects made in detail and by constructing rules of thumb that matched these subjects' observed choices. Three main rules of thumb appeared to be effective in the different games. A first rule "When nothing in stock go to EDLP and stock up" effectively protected respondents from having to buy expensive products in the Hi-Lo store. When combined with a second rule "When all products are in stock go to Hi-Lo", the first rule allowed consumers to go to the Hi-Lo store and benefit from discounted products without having to purchase expensive products. A third rule "When in Hi-Lo stock up on discounted products" further reinforced this positive effect of benefiting from discounts. Computer simulations of the effect of applying these rules in the different conditions revealed that they allowed for performances that were quite close to optimal. It is interesting to see that only few subjects achieved this level of performance and we conclude that only few individuals were using the most effective heuristics. This implies that subjects must have used other heuristics as well.

Our results have implications for consumers, online intermediaries and retailers. First, our finding that price disclosure causes consumers' choices to deviate more sharply from a normative model opens up the opportunity, in information-rich retailing environments, of offering them decision support to improve the quality of their decisions (and hence their welfare). The Internet seems a particularly appropriate medium through which to provide such support. Indeed, some online intermediaries currently offer services that are consistent with this 
idea. For example, valupage .com allows consumers to download retail coupons for up to a week in advance, while mybudgetplanner . com helps consumers to better plan their purchases over time. Even those online and traditional retailers that use direct personalized e-mails to preannounce specials to valued loyal customers also—perhaps unintentionally—assist target consumers with their dynamic shopping decisions.

Second, our results show that, ceteris paribus, in the no and current price disclosure conditions of our experiment, consumers preferred Hi-Lo over EDLP in terms of store price format. It should be noted, however, that in (online) retailing environments in which information levels on current prices are relatively high, this information encourages consumers to shop at $\mathrm{Hi}-$ Lo stores only when items are on discount. Therefore, retailers who employ a Hi-Lo strategy may be hurt considerably more when current prices are placed online than retailers employing an EDLP strategy are.

This research has some limitations that offer up opportunities for future research. We focused on cost minimization in dynamic shopping decisions given fixed consumption rates. Although costs are an important factor in consumer decision-making, product preferences and actual consumption rates are also clearly important. Our model and experiment also ignore the effect of holding costs on stocking behavior, and these costs may be an important influence on purchase quantity decisions as well (Assunçao and Meyer, 1993). If holding costs are introduced in the model, the normative model structure would be largely the same, with an additive penalty for stocking up for future periods. However, the presence of holding costs would further complicate the subjects' optimization task which may cause consumers to benefit less from price disclosure, even in the current price disclosure conditions. 
Although our model allows for heteroscedasticity between price information conditions, we did not include possible differences in error structure in the decisions within and across periods. By doing so, future research would enable a deeper exploration of variations in consumer choice consistency between decisions. More generally, it would be worthwhile in future to explore the modeling of subjects' use of heuristics in a more direct fashion, for example, by estimating the likelihood of use of different predefined heuristics. Another relevant topic for future research is to disentangle subjects' non-normative price expectations from their non-normative purchase decisions. In our model these two effects were not separated.

Finally, while we took steps to maximize the external validity and realism of our experiment by developing an Internet-based shopping game, by using real-world consumers, and by rewarding them to ensure appropriate levels of motivation, it would be interesting to extend this study to an entirely real-world retail setting, for instance by conducting an in-store field experiment.

In sum, despite the limitations of this paper, we believe it takes an important first step in setting the direction for future research on the influence of price disclosure on consumers' dynamic shopping decisions. 


\section{References}

Allenby, Greg M., and James L. Ginter. (1995). “The Effects of In-Store Displays and Feature Advertising on Considerations Sets,” International Journal of Research in Marketing 12(1), 67-80.

Assunçao, Joao L., and Robert J. Meyer. (1993). “The Rational Effect of Price Promotion on Sales and Consumption,” Management Science, 39(5), 517-535.

Bell, David R., Jeongwen Chiang, and V. Padmanabhan. (1999). “The Decompositional Effect of Promotional Response: An Empirical Generalization,” Marketing Science 18(4), 504526.

Bell, David R. and James M. Lattin. (1998). “Shopping Behavior and Consumer Preference for Store Price Format: Why “Large Basket” Shoppers Prefer EDLP,” Marketing Science 17(1), 66-88.

Bellman, Richard. (1957). Dynamic Programming. Princeton, NJ: Princeton University Press.

Bettman, James R., Eric J. Johnson, and John W. Payne. (1990). “A Componential Analysis of Cognitive Effort in Choice,” Organizational Behavior and Human Decision Processes 45(1), 111-140.

Bettman, James R., Eric J. Johnson, Mary Frances Luce, and John W. Payne. (1993). “Correlation, Conflict and Choice,” Journal of Experimental Psychological: Learning, Memory and Cognition 19(4), 931-950.

Brynjolfsson, Eric, and Michael D. Smith (2000). “Frictionless Commerce? A Comparison of Internet and Conventional Retailers,” Management Science 46(4), 563-585.

DeGroot, Morris. (1970). Optimal Statistical Decisions, New York: McGraw-Hill. 
Dellaert, Benedict G.C., Jeff D. Brazell, and Jordan J. Louviere. (1999), “The Effect of Attribute Variation on Consumer Choice Consistency,” Marketing Letters 10(2), 139-147.

Erdem, Tülin, and Michael P. Keane. (1996). “Decision-making Under Uncertainty: Capturing Dynamic Brand Choice Processes in Turbulent Consumer Goods Markets,” Marketing Science 15(1), 1-20.

Hutchinson, J. Wesley, and Robert J. Meyer. (1994). “Dynamic Decision Making: Optimal Policies and Actual Behavior in Sequential Choice Problems," Marketing Letters 5(4), 369-382.

Kahn, Barbara E. and David C. Schmittlein. (1989). "Shopping Trip Behavior: An Empirical Investigation,” Marketing Letters, 1(1), 55-69

Krishna, Aradhna. (1994a). “The Impact of Dealing Patterns on Purchase Behavior,” Marketing Science 13(4), 351-373.

Krishna, Aradhna. (1994b). "The Effect of Deal Knowledge on Consumer Purchase Behavior,” Journal of Marketing Research 31(1), 76-91.

Meyer, Robert J., and Joao L. Assunçao. (1990). “The Optimality of Consumer Stockpiling Strategies,” Marketing Science 9(1), 18-41.

Swait, Joffre D., and Victor Adamowicz. (2001a). “The Influence of Task Complexity on Consumer Choice: A Latent Class Model of Decision Strategy Switching,” Journal of Consumer Research 28(1), 135-148.

Swait, Joffre D., and Victor Adamowicz (2001b). “Choice Environment, Market Complexity, and Consumer Behavior: A Theoretical and Empirical Approach for Incorporating Decision Complexity into Models of Consumer Choice,” Organizational Behavior and Human Decision Processes 86(2), 141-167. 
Table 1 Actual and normative consumer spending

\begin{tabular}{|c|c|c|c|}
\hline & $\begin{array}{c}\text { Actual average } \\
\text { spending }\end{array}$ & $\begin{array}{l}\text { Difference in } \\
\text { spending }\end{array}$ & $\begin{array}{l}\text { Normative model } \\
\text { spending }\end{array}$ \\
\hline $\begin{array}{l}\text { Game 1a } \\
\text { No price disclosure } \\
\text { Hi-Lo preferred }\end{array}$ & $\begin{array}{l}266.6 \\
(10.5)\end{array}$ & $8.8^{*}$ & 257.8 \\
\hline Effect of price disclosure & $23 *$ & -1.8 & 24.8 \\
\hline $\begin{array}{l}\text { Game 2a } \\
\text { Current price disclosure } \\
\text { Hi-Lo preferred }\end{array}$ & $\begin{array}{l}243.6 \\
(15.3)\end{array}$ & $10.6^{*}$ & 233.0 \\
\hline Effect of price disclosure & $6.4^{*}$ & $-4.7 * *$ & 11.1 \\
\hline $\begin{array}{l}\text { Game 3a } \\
\text { Future price disclosure } \\
\text { Hi-Lo preferred }\end{array}$ & $\begin{array}{l}237.2 \\
(11.8)\end{array}$ & $15.3^{*}$ & 221.9 \\
\hline $\begin{array}{l}\text { Game } 1 b \\
\text { No price disclosure } \\
\text { EDLP preferred }\end{array}$ & $\begin{array}{c}266.1 \\
(8.1)\end{array}$ & $10.2^{*}$ & 255.9 \\
\hline Effect of price disclosure & $25.1 *$ & 0.0 & 25.1 \\
\hline $\begin{array}{l}\text { Game } 2 \mathrm{~b} \\
\text { Current price disclosure } \\
\text { EDLP preferred }\end{array}$ & $\begin{array}{l}241.0 \\
(7.6)\end{array}$ & $10.2^{*}$ & 230.8 \\
\hline Effect of price disclosure & $4.6^{*}$ & $-4.1^{*}$ & 8.7 \\
\hline $\begin{array}{l}\text { Game 3b } \\
\text { Future price disclosure } \\
\text { EDLP preferred }\end{array}$ & $\begin{array}{l}236.4 \\
(6.4)\end{array}$ & $14.3^{*}$ & 222.1 \\
\hline
\end{tabular}

$\S$ Standard deviation of actual spending is in parentheses.

* Significant at $95 \%$ confidence level

** Significant at $90 \%$ confidence level 
Table 2 Dynamic choice model estimates*

\begin{tabular}{|c|c|c|c|}
\hline Scenario & Variable & $\begin{array}{l}\text { Parameter } \\
\text { estimate }\end{array}$ & t-value \\
\hline \multirow[t]{3}{*}{$\begin{array}{l}\text { No price disclosure } \\
\text { (games 1a and 1b): }\end{array}$} & $\begin{array}{l}\text { Store price format } \\
\text { preference } \\
(\text { Hi-Lo) }(\beta)\end{array}$ & $0.184^{*}$ & 14.422 \\
\hline & $\begin{array}{l}\text { Reduced forward- } \\
\text { looking }(\delta)\end{array}$ & 0.086 & 1.548 \\
\hline & $\begin{array}{l}\text { Scale parameter } \\
(\lambda)\end{array}$ & $-0.670 *$ & -12.676 \\
\hline \multirow[t]{3}{*}{$\begin{array}{l}\text { Current price } \\
\text { disclosure } \\
\text { (games 2a and 2b) }\end{array}$} & $\begin{array}{l}\text { Store price format } \\
\text { preference } \\
(\text { Hi-Lo) }(\beta)\end{array}$ & $0.469 *$ & 2.465 \\
\hline & $\begin{array}{l}\text { Reduced forward- } \\
\text { looking }(\delta)\end{array}$ & $0.937^{*}$ & 21.970 \\
\hline & $\begin{array}{l}\text { Scale parameter } \\
(\lambda)\end{array}$ & $-1.527^{*}$ & -25.319 \\
\hline \multirow[t]{3}{*}{$\begin{array}{l}\text { Future price disclosure } \\
\text { (games } 3 \mathrm{a} \text { and } 3 \mathrm{~b} \text { ) }\end{array}$} & $\begin{array}{l}\text { Store price format } \\
\text { preference } \\
(\text { Hi-Lo) }(\beta)\end{array}$ & $0.343^{* *}$ & 1.701 \\
\hline & $\begin{array}{l}\text { Reduced forward- } \\
\text { looking }(\delta)\end{array}$ & $0.436^{*}$ & 13.154 \\
\hline & $\begin{array}{c}\text { Scale parameter } \\
(\lambda)\end{array}$ & $-0.995^{*}$ & -30.174 \\
\hline
\end{tabular}

* Significant at $95 \%$ confidence level

** Significant at $90 \%$ confidence level 


\section{Appendix 1. Model Assumptions and Experimental Context}

Our model is closely connected to our Internet-based experiment in which we control for several decision variables that consumers may also integrate in their real-world purchase decisions. Thus, because of our focus on investigating the role of price information disclosure on consumers' shopping decisions, our model is also in some ways more restrictive than existing models of dynamic decisions making.

First, we imposed the condition that consumers purchase their groceries at regular intervals. Although a simplification of reality, this feature is consistent with behavior observed for most grocery purchases which are made in weekly or bi-weekly intervals. For example, Kahn and Schmittlein (1989) observed that products such as toilet paper, baked beans and crackers are all bought on regular weekly shopping trips.

Second, we did not investigate consumption goals but took them as given in the consumer cost minimization task. Taking consumption goals as known is reasonable in many product categories, especially for frequently purchased grocery goods in which consumption rates are stable, but may not be realistic for all products (e.g., Bell, Chiang \& Padmanabhan 1999). We also fixed consumption rates in the experiment. However, our model of shopping decisions would allow for flexible consumption as long as consumption goals were known to the consumer at the time of purchase.

Third, in our experiment we allowed consumers to change stores from trip to trip, but visit only one store per trip. As we explained to subjects, this situation is comparable to one where the fixed costs of going to a store (or the costs of ordering and delivery in the Internet context) are high enough that visiting (or ordering from) multiple stores is always more costly than the potential reduction in price from buying in multiple stores.

Fourth, because of our focus on shopping choice, we were not interested in brand or product choice. Therefore, we indicated to subjects that all available grocery stores carried perfect substitutes for all products. Stores differed only in their pricing of these substitutes and in the degree to which future prices are communicated.

Fifth, we imposed some stocking restrictions. Products could only be stocked for a maximum storage period, resembling the effect of spoilage. In contrast to several previous models (e.g., Krishna 1994a) we did not impose flexible stocking costs. The reason we imposed a stocking restriction in this way is to mimic the budget optimization task most consumers face. Typically consumers do not face regular out-of-pocket expenses for stocking consumer products. Rather consumers are restricted by (rare) discrete decisions they make about their stocking capacity at home (e.g., to buy an additional refrigerator or not).

Sixth, we set up the model and experiment in such a way that a normative model does not require discounting of future prices. The reason we chose this level is because we expect it to be the level that is simplest for consumers to process and leaves the least room for perceptual error on the part of subjects. As a consequence, setting the normative discount level to zero allows for a more straightforward test of variations in the degree of forward-looking in consumer decisionmaking: If variations in discounting are observed in our analysis, it represents a clear rejection of the normative model.

Finally, we informed subjects that prices in the stores took on a discrete probability distribution with no memory over periods. Doing so allowed for a more direct test of consumer shopping decision-making, because no consumer learning or forward looking was required in predicting the probability of discounts. 


\section{Technical Appendix}

\section{Solution of the consumer dynamic programming problem}

This appendix provides the solution to the consumer's dynamic programming problem for periods T and T-1 starting from the last period. Solutions for other periods are reached using backward induction, repeating the steps described in this appendix.

Let $Q_{n t w}$ be the quantity of product $n$ bought in week $w$ that remains at the end of week $t$ (net of quantity that was consumed and that spoiled) and $C_{n t \mathrm{w}}$ be the quantity of product $n$ bought in week $w$ and consumed in week $t$. Let $A_{n}$ be the maximum number of weeks that product $n$ can be stored after purchase. Then, we express $Q_{n t w}$ as follows (see equation 1 to 3 for definitions of the other variables):

$$
Q_{n t w}= \begin{cases}q_{n t \alpha}-\sum_{j=w}^{t} C_{n j w,} & \text { if } w>\left(t-A_{n}\right) \\ 0, & \text { if } 0<w \leq\left(t-A_{n}\right)\end{cases}
$$

Further, the total amount of product $n$ in stock at the end of week $t$ is defined as:

$$
Q_{n t}=\sum_{w=1}^{t} Q_{n t w}
$$

The consumer's dynamic optimization problem can be solved by backward induction. We start with the last period $T$ and calculate the minimal total expected cost (spending + store preference) at time $T$ as a function of $Q_{n(T-1)}$, the total quantity of product $n$ remaining in stock at the end of week $T-1$. The consumer chooses the store to visit $s_{T}$ and the quantity to buy $q_{n t \alpha}$.

$$
\left\{s_{T}\left(Q_{n(T-1)}\right), q_{n T \alpha}\left(Q_{n(T-1)}\right)\right\}=\arg \min _{s_{T} q_{n T \alpha}}\left[\sum_{n \in N} \sum_{\alpha \in \Psi_{n s T}} \operatorname{Pr}\left(p_{n s_{T} \alpha}\right) q_{n T \alpha}\left(Q_{n(T-1)}\right) p_{n s_{T} \alpha}\right]
$$

Next, we can calculate the minimal expected cost at $T-1$ as a function $Q_{n(T-2)}$. $Q_{n T-1}$ can be calculated based on $Q_{n T-2}, s_{T-1}$ and $q_{n(T-1) \alpha}$.

$$
\begin{aligned}
\left\{s_{T-1}\left(Q_{n(T-2)}\right), q_{n(T-1) \alpha}\left(Q_{n(T-2)}\right)\right\}= & \arg \min _{s_{T-1}, q_{n(T-1) \alpha}} \sum_{n \in N} \sum_{\alpha \in \Psi_{n s(T-1)}} \operatorname{Pr}\left(p_{n s_{T-1} \alpha}\right) q_{n(T-1) \alpha}\left(Q_{n(T-2)}\right) p_{n s_{T-1} \alpha} \\
& \left.+e^{-\gamma}\left(\sum_{n \in N} \sum_{\alpha \in \Psi_{n s T}} \operatorname{Pr}\left(p_{n s_{T} \alpha}\right) q_{n T \alpha}\left(Q_{n(T-1)}\right) p_{n s_{T} \alpha}\right)\right]
\end{aligned}
$$

This process of backward induction is repeated until the period in which the current consumer decision takes place. Thus, it can provide a solution for any given period. 


\section{Segmentation analysis}

To allow for possible heterogeneity in subject behavior we estimated a conditional random coefficients version of the models for the forward-looking parameters. In these models a discrete heterogeneity distribution was used to approximate the underlying distribution of the forward-looking parameters. Maximum likelihood was used in the estimation which involved both the estimation of the equivalent of the parameters in the aggregate model for each segment and the estimation of the probability masses of the distribution of the parameter values. Jain, Vilcassim and Chintagunta (1994) provide details on the likelihood function for the static case, which is comparable to the optimization in each period in our model. The optimal number of segments for each parameter and each price level information condition was determined based on the Bayesian Information Criterion (BIC).

The results of the heterogeneity analysis are presented in Table S1 and showed that there were two segments for the no price disclosure condition and three segments for the current and future price disclosure conditions. The probability masses for the three segments in the latter two conditions were more or less equal (around 0.33 probability) and the parameter estimates fairly symmetric around the middle value. This result indicated that there were no clear discrete differences between respondents (e.g., due to differences in choice strategy), but that respondents differed on a more or less continuous scale in terms of the degree to which they were forwardlooking. In the no price disclosure condition, however, segments were more different in size, with one distinct segment performing close to optimal.

\section{Reference}

Jain, Dipak C., and Naufel J. Vilcassim, and Pradeep K. Chintagunta. (1994). “A RandomCoefficients Logit Brand-Choice Model Applied to Panel Data,” Journal of Business and Economic Statistics 12(3), 317-328. 


\section{Table S1 Forward-looking based segmentation **}

\begin{tabular}{|c|c|c|c|c|c|c|}
\hline Scenario & $\begin{array}{l}2 \text { segment } \\
\text { estimates }\end{array}$ & $\begin{array}{l}\text { Relative } \\
\text { segment } \\
\text { size }\end{array}$ & $\begin{array}{l}3 \text { segment } \\
\text { estimates }\end{array}$ & $\begin{array}{l}\text { Relative } \\
\text { segment } \\
\text { size }\end{array}$ & $\begin{array}{l}4 \text { segment } \\
\text { estimates }\end{array}$ & $\begin{array}{l}\text { Relative } \\
\text { segment } \\
\text { size }\end{array}$ \\
\hline \multirow{3}{*}{$\begin{array}{l}\text { No price disclosure } \\
\text { (games 1a and 1b) }\end{array}$} & 0.065 & 0.173 & 0.065 & 0.175 & \multirow[t]{3}{*}{ - } & \\
\hline & \multirow[t]{2}{*}{0.113} & \multirow[t]{2}{*}{0.827} & 0.112 & 0.412 & & \\
\hline & & & 0.113 & 0.413 & & \\
\hline $\begin{array}{r}\text { Loglikelihood } \\
\text { improvement }\end{array}$ & \multicolumn{2}{|l|}{$87.32 *$} & \multicolumn{2}{|l|}{4.37} & & \\
\hline \multirow{4}{*}{$\begin{array}{l}\text { Current price } \\
\text { disclosure } \\
\text { (games 2a and 2b) }\end{array}$} & \multirow{4}{*}{$\begin{array}{l}0.580 \\
1.279\end{array}$} & \multirow{4}{*}{$\begin{array}{l}0.462 \\
0.538\end{array}$} & 0.450 & 0.336 & 0.350 & \multirow{4}{*}{$\begin{array}{l}0.268 \\
0.220 \\
0.234 \\
0.278\end{array}$} \\
\hline & & & 0.961 & 0.303 & 0.848 & \\
\hline & & & 1.432 & 0.361 & 1.016 & \\
\hline & & & & & 1.523 & \\
\hline $\begin{array}{r}\text { Loglikelihood } \\
\text { improvement }\end{array}$ & $69.73^{*}$ & & $15.84^{*}$ & & 4.11 & \\
\hline \multirow{4}{*}{$\begin{array}{l}\text { Future price } \\
\text { disclosure } \\
\text { (games 3a and 3b) }\end{array}$} & \multirow{4}{*}{$\begin{array}{l}0.234 \\
0.642\end{array}$} & \multirow{4}{*}{$\begin{array}{l}0.489 \\
0.511\end{array}$} & 0.171 & 0.311 & 0.118 & 0.250 \\
\hline & & & 0.446 & 0.357 & 0.410 & 0.242 \\
\hline & & & 0.711 & 0.332 & 0.524 & 0.260 \\
\hline & & & & & 0.742 & 0.248 \\
\hline $\begin{array}{r}\text { Loglikelihood } \\
\text { improvement }\end{array}$ & $21.09 *$ & & $12.74^{*}$ & & 2.22 & \\
\hline
\end{tabular}

* Significant at 95\% confidence level for using one additional degree of freedom (based on BIC criterion)

** Segmentation conditional on estimates for average store preference and price parameters per condition (Table 1) 